\title{
Evaluation of caving as a mining method for the Udachnaya underground diamond mine project
}

M Tishkov ALROSA PJSC, Russia

\begin{abstract}
Hydraulic radius is calculated to assess the size of undercut to ensure the caveability of an orebody. There are two options for undercutting the kimberlite pipe of Udachny. Both options have a variety of configurations and design elements to create an area to initiate and propagate the cave. The first option has a single undercut horizon, while the second employs two undercut horizons. In the latter case, in addition to the primary horizon, there is another undercutting horizon to cave an upper block. The order of mining (eastern and western), the placement and spacing of drawpoints, the specific volume of infrastructure development mining, and the volume of mined ore columns are then determined.
\end{abstract}

\section{Introduction}

The Udachnaya pipe diamond deposit extends from the surface to a depth of $250 \mathrm{~m}$, below which it was divided into two separate cone-shaped orebodies: the western orebody (WOB) and the eastern orebody (EOB). Figure 1 shows a three-dimensional model of the orebodies and open pit.

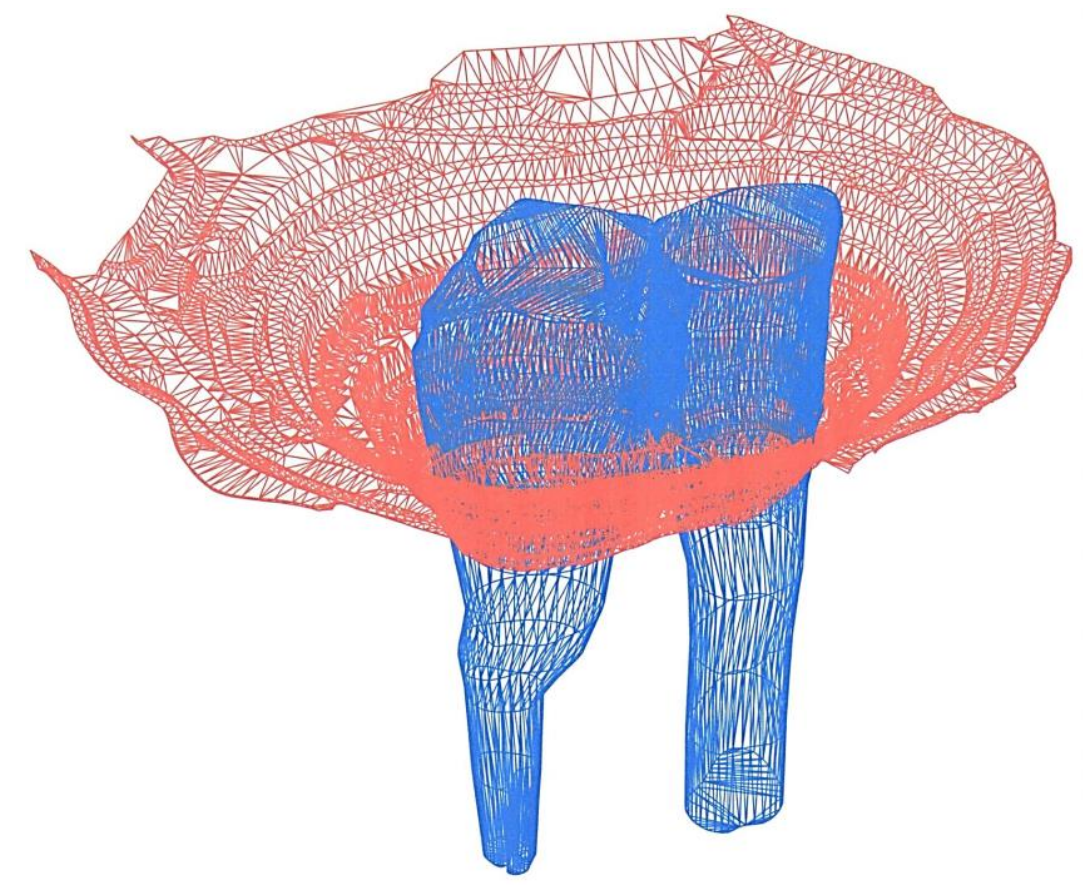

Figure 1 Composite wireframe model

At present, both orebodies are developed by open pit to a depth of $-320 \mathrm{~m}$. They are separated by a block of Upper Cambrian sedimentary rocks. The lateral distance between the orebodies in the interval of $-320 /-1,280$ $\mathrm{m}$ varies from 90 to $325 \mathrm{~m}$. The sedimentary rock mass separating the orebodies in the junction zone is highly faulted and folded. Figure 2 shows a vertical geological section. 


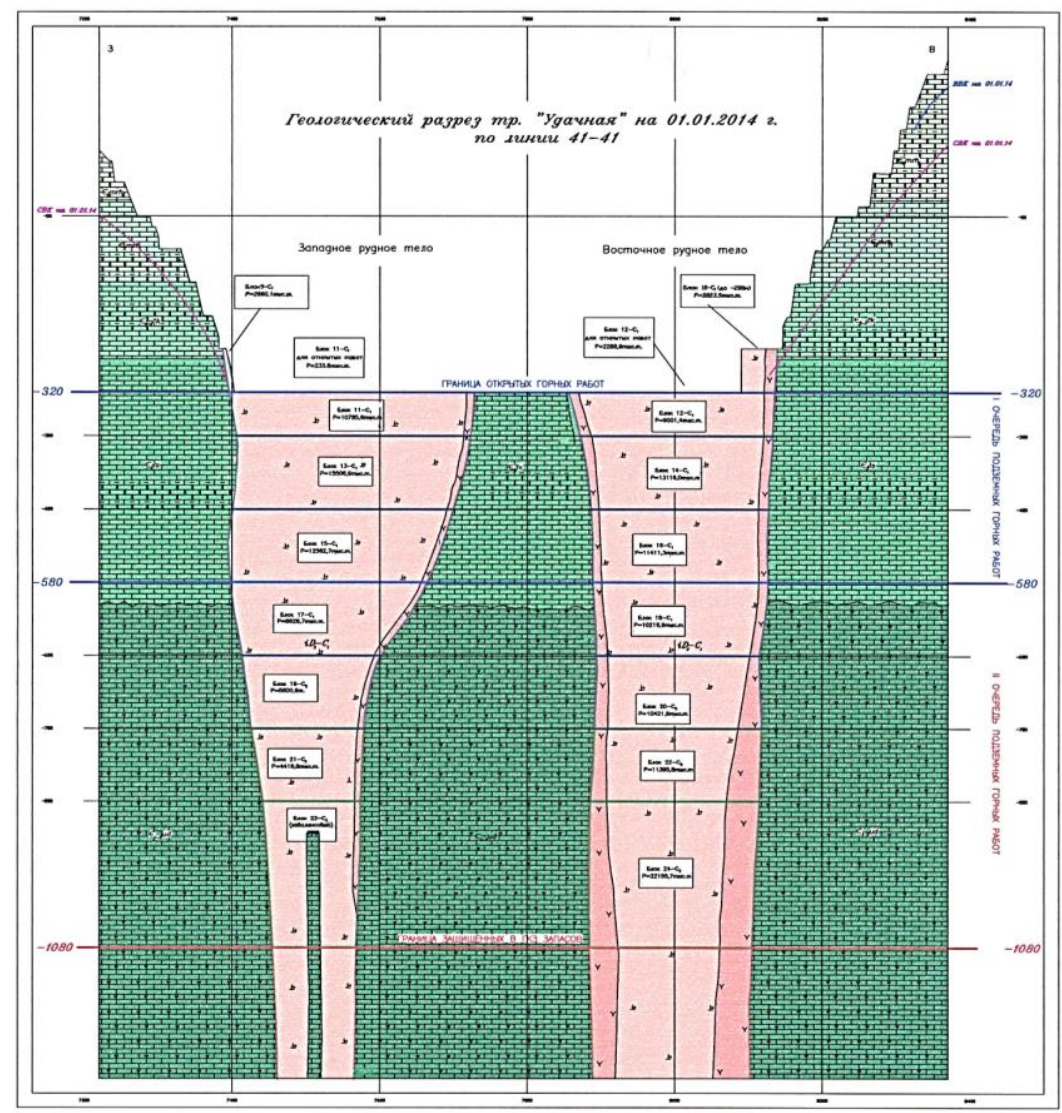

Figure 2 Geological cross-section of the Udachnaya pipe

The footprint of the WOB is of ellipsoidal shape elongated towards the northwest. The shape of horizontal sections changes with depth, becoming more isometric. Ore and host rock contacts are well-defined. 'Floating' contacts resulting from brecciation of the host rock within proximate outer exo-contact are rarely seen. The structure of the WOB is fairly discontinuous. Autolithic kimberlite breccia prevails in the orebody, while in the marginal parts of the diatreme, relicts of the porphyry kimberlite formed at the early stage of kimberlite formation, are often observed.

The EOB has an ellipsoidal shape in plan view, somewhat elongated in the northeasterly direction. The contours of the orebody in the horizontal sections are quite smooth. Contacts of the orebody with host rocks are mainly sharp, and in rare cases, 'floating', due to brecciation of host rocks in the zone of proximate exo-contact.

During geological mapping of the Udachnaya pipe pit walls, two main directions of the joints in the host rocks were identified, one dipping northeast (strike azimuth from 75 to $80^{\circ}$, and angle of incidence from 80 to $88^{\circ}$ ) and the second dipping northwest (with angles of incidence from 80 to $90^{\circ}$ ). Vertical displacements along jointing zones, as well as breccia zones, are absent. In addition to the jointing zones found in the walls of the open pit, areas of increased and intensive jointing (fragmentation zones) of the host rocks are distinguished within the prevailing background.

The intensity of jointing sharply decreases with depth. The main tectonic disturbances are shown in Figure 3. 


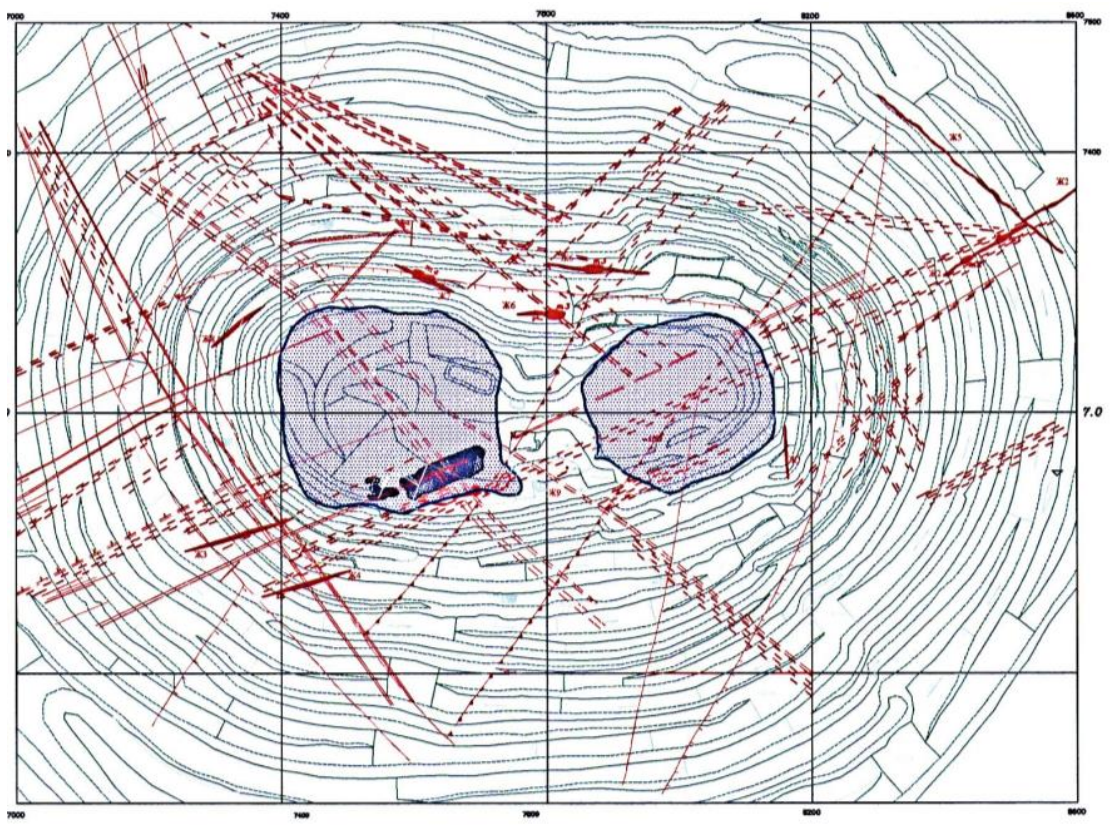

Figure 3 Geological structural plan view of the Udachnaya kimberlite pipe

The WOB kimberlite represents a typical breccia with a large (up to $80 \%$ ) content of xenoliths of different origin. It is a dense greenish or bluish-grey carbonised rock, reminiscent of volcanic tuff breccias.

The EOB kimberlite is a dense rock of porphyry-like structure of dark green to black-green colour. Unlike the WOB kimberlite, the EOB kimberlite contains numerous fragments of fresh olivine; there are also rounded grains of pyrope and ilmenite. Maximum ore grade of the EOB is $35 \%$ less than the maximum grade of the WOB.

Orebodies of the deposit have a relatively simple shape, and are characterised by a heterogeneous internal structure with varying distribution of diamonds, due to the presence of two intrusion phase kimberlites (kimberlite breccia and porphyry kimberlite), as well as the presence of large xenoliths of host rocks; the so-called 'floating reefs' in the ore.

The Udachny mine falls into the category of dangerous due to the release of combustible gases and petroleum bitumen. The gas-bearing properties of the deposit are due to the presence of gases dissolved in oil and brines, and the rocks as such virtually do not have any sorption capacity.

The nature of oil and bitumen occurring in the host rocks differs from that in the kimberlites; there is no clear spatial relationship between them. Results of the visual examination of the core samples prove that the oil saturation of the kimberlites is generally several times less than that of the host rocks.

According to the results of luminescent microscopic studies, dispersed-scattered oil is found throughout the entire kimberlite rock mass. The WOB is more intensively saturated with oil and bitumen throughout the explored depth.

One of the most challenging scientific and engineering problems is the substantiation of mining method and the selection of mining system suitable for development of the deposits with complex rock conditions and adverse geological and mining conditions. The latter includes the Udachnaya kimberlite pipe, which is characterised by the presence of aquifers, intermittency of rocks with abruptly changing physical, mechanical and strength properties, low strength of ore due to the presence of water, fracturing, gas saturation, and ingress of petroleum bitumen.

The development of the deposit is done via three shafts located outside of the estimated zone of mining impact. 
The development workings of the Udachnaya underground project are:

- Skip shaft (SS): for ore hoisting, exhaust air discharge, and emergency exit.

- Cage shaft (CS): for fresh air supply, and delivery of large-sized equipment onto the levels.

- Ventilation auxiliary shaft (VAS): for hoisting of people, materials, equipment, rock hoisting after driving of the tunnels, fresh air supply, water drainage, and emergency exit.

The scheme of development of the deposit is shown in Figure 4.

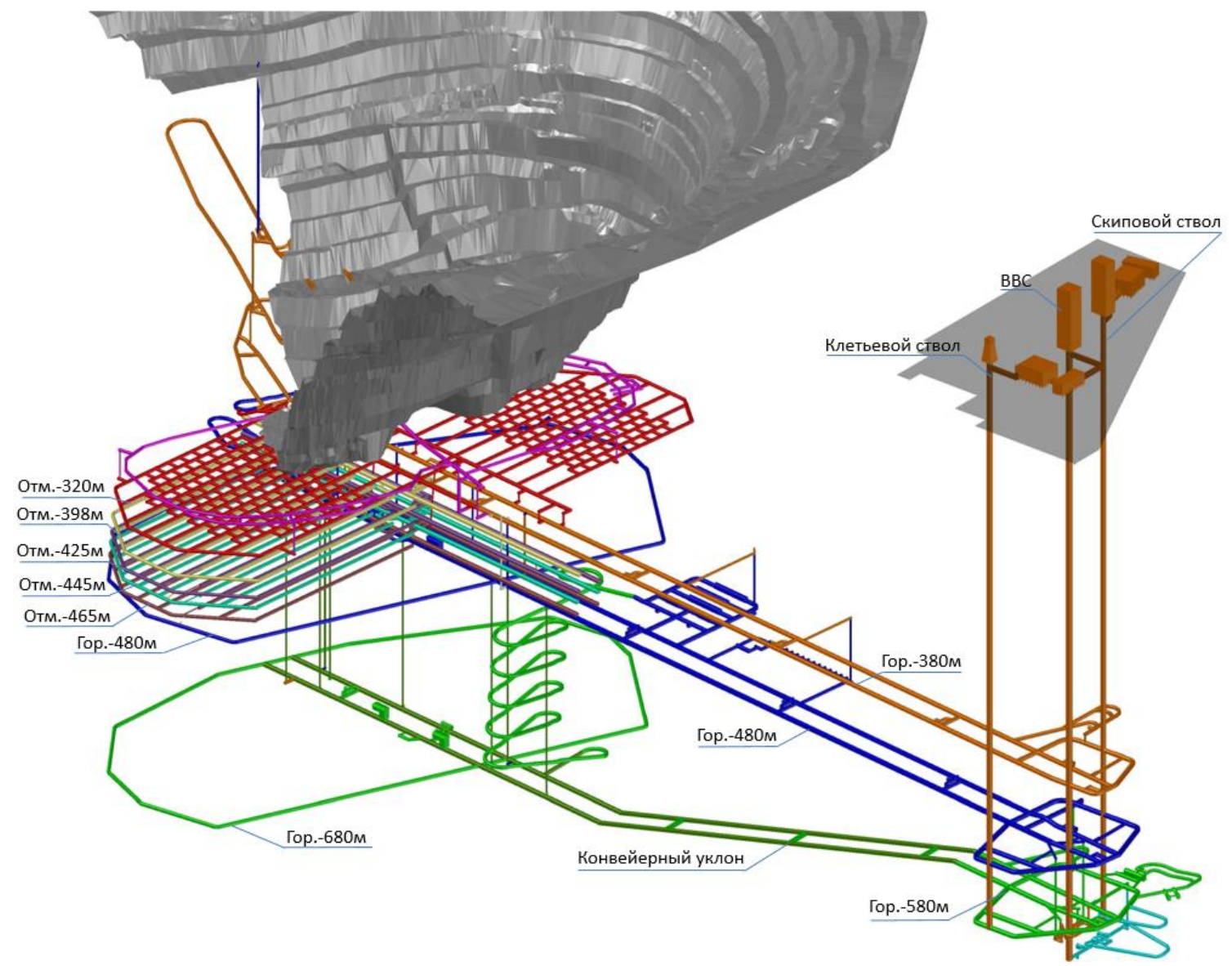

Figure 4 Scheme of the deposit development

In accordance with the adopted design solutions, the deposit is being developed by induced caving: the contact-adjacent reserves at $-265 /-320 \mathrm{~m}$ by sublevel open-bench mining, and the rest of Block 1 at -320/-365 $m$ with a single-stage extraction with continuous draw across the entire footprint. Block 2 is to be mined in similar fashion down to the -480 Level.

At present, there is no operational underground project which mines diamondiferous kimberlite ore using the caving mining method in such adverse conditions of cryolithozone. Existing diamond mines, which operate in similar climatic and geological conditions, typically develop kimberlite resources by underground mining systems such as slicing or room-and-pillar method with consolidating backfill. A number of underground kimberlite mines in South Africa and Australia (including Cullinan, Finsch and Argyle) use sublevel or block caving methods. The mining is carried out under complex mining and geological conditions due to the poor stability of both ore and host rock, and due to the influence of water infiltration. When selecting the cave mining method for extraction of the reserves, block caving is typically preferred. 


\section{System validation approaches}

During 2014-2018, the specialists of Yakutniproalmaz Institute of ALROSA PJSC carried out a study for the substantiation of the block caving mining method for development of Block 3/4 (MB2 at -480/-680 Levels) of the Udachnaya kimberlite deposit. It has been established that the caving of the block or panel is initiated by undercutting, in order for the hydraulic radius to reach or exceed the critical value.

The vertical propagation of the cave will result from the continuous extraction of the broken ore through the operational drawpoints. The horizontal propagation of the cave will be coordinated with the commissioning of a number of ore handling stations located below the undercut level.

The evidence-based data obtained from a number of mines show that undercutting makes a major contribution to the success of block caving. The control of the undercutting process has a dominant influence on productivity and production costs (Brown 2002). Special emphasis is placed on the fact that undercutting increases the abutment pressure in the host rocks and in the roadways of the haulage levels, which in turn can contribute to delays in production and excessive costs for roadway maintenance and support. While developing the undercut, it is necessary to ensure:

- Creating an initial undercut sufficient to induce the caving process.

- Working out the required undercut while avoiding the host rock.

- Time-dependent development of the undercut to achieve the hydraulic radius, initiation of caving and propagation of cave with simultaneous decrease of abutment pressure in the undercut area.

Successful undercutting and subsequent cave propagation requires close attention to a number of factors including:

- Sequence of development of undercutting and drawbells opening at the production level.

- Relative location and spacing of undercutting face and production face of the production level.

- Starting point and direction of the development of the undercut.

- Speed of undercutting.

- Height of the undercut.

- Geometry of the undercut, including sectional and plan view.

Although undercutting is the primary means of initiating the caving process, additional measures may be required to promote cave propagation by forming additional fractures. To determine the possibility of using the caving mining method, the options for creating favourable conditions for the cave propagation in Udachnaya mine were studied. Options included various size-shape parameters of the undercut (Figure 5). 


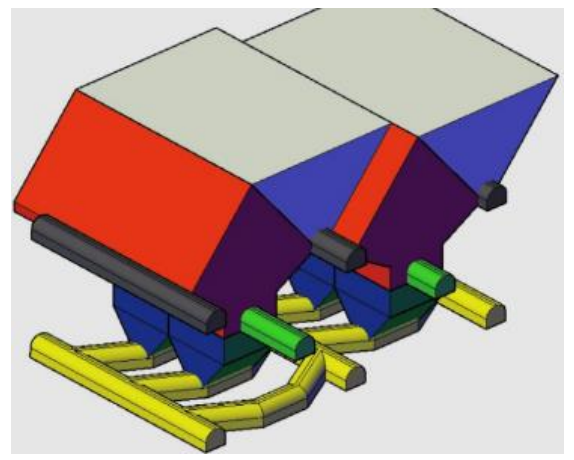

(a)

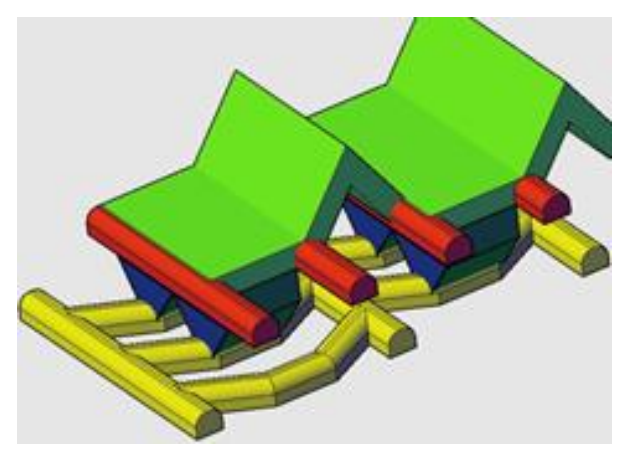

(c)

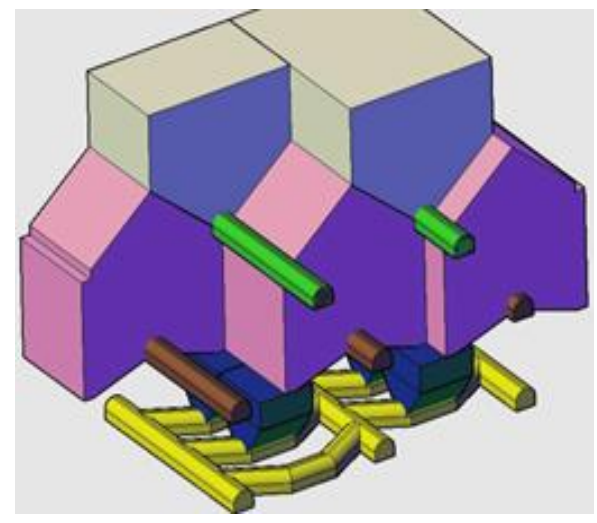

(e)

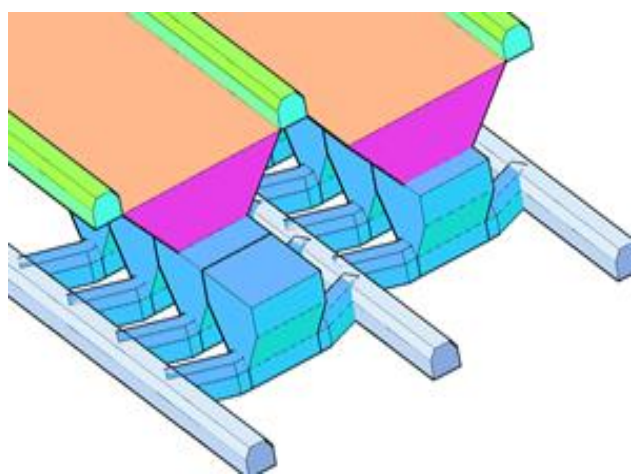

(b)

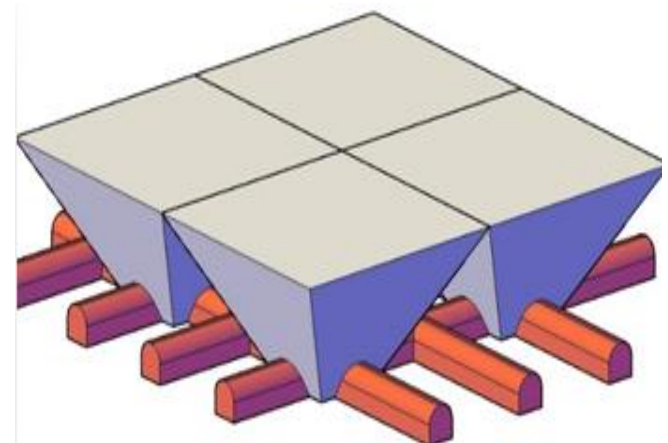

(d)

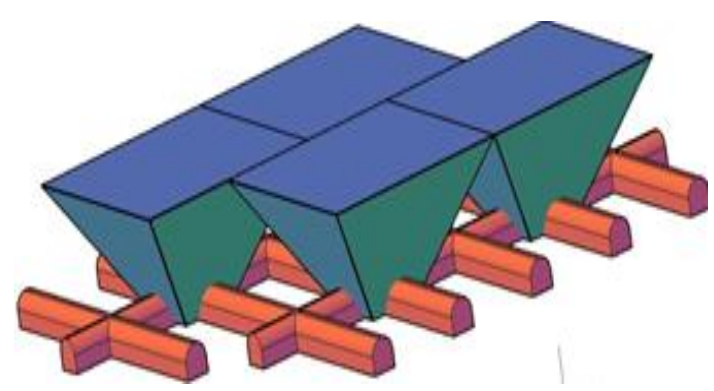

(f)

Figure 5 Options of undercutting and draw level configurations considered for implementation; (a) Design of the bottom of the block (a drawpoint with a double low undercutting); (b) Design of the bottom of the block (a drawpoint with a double low undercutting), with modified lower trench undercutting; (c) Design of the bottom of the block with saw-tooth pattern undercutting; (d) Design of the drawpoint with aligning arrangement of the bells and four loading points; (e) Design of the bottom of the block with a double low undercutting; and, (f) Drawpoint design with the staggered arrangement of the bells and four loading points 
The methods developed to date by a number of authors (i.e. Laubscher, Mathews, Potvin, Mawdesley) for assessing the conditions necessary for the progress of caving are based on the rating evaluation of the rock mass and the determination of the required value of the hydraulic radius, determined by the area and shape of the undercutting (Laubscher 2001, Mawdesley 2002). Assessment of the stability of the outcrop (the possibility of spontaneous caving) is made according to a diagram drawn on the evidence-based data obtained from a number of mines worldwide. The term hydraulic radius (HR) is understood to be the ratio of the area of exposure of hanging wall (or roof) to its perimeter. If the stope is inclined, then the most critical element is the exposure of the hanging wall (Figure 6). In this case, in the calculation of HR, the spans of the stopes are used along the dip (h) and along the strike (w).

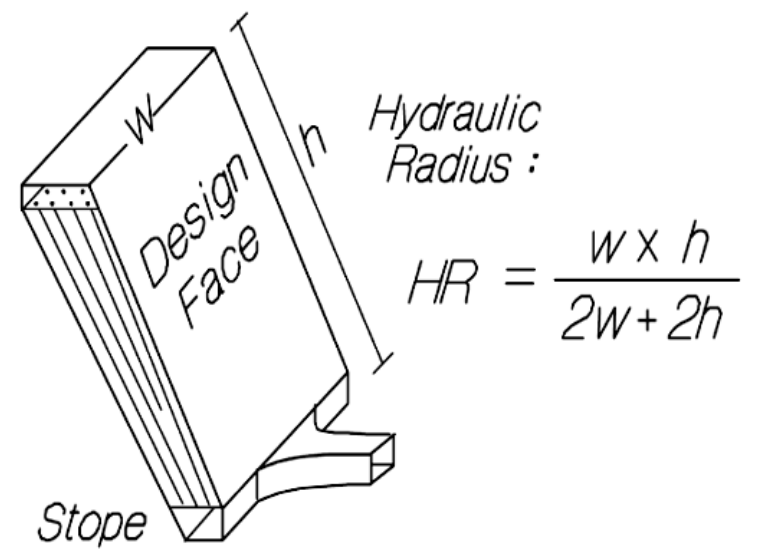

Figure 6 HR calculation scheme

Over the past ten years, a database of anecdotal evidence on the caving conditions for the rocks of medium to high strength and stability has been intensively enriched. When updating the database, the criteria for the transition of the rock mass from a stable to an unstable state (with the formation of a cave) becomes more specific. The unstable state implies possible ultimate caving of the undercut rock mass and eliminating hang-ups.

For the conditions of the Udachnaya mine, the $18 \mathrm{~m} \mathrm{HR}$ was calculated, taking into account safety and reliability requirements. The results of calculations of the HR are given in Table 1.

\section{Table 1 HR calculation results}

\begin{tabular}{lll}
\hline No. & Calculation method & HR $(\mathbf{m})$ \\
\hline 1 & Mathews, Potvin & 13 \\
2 & Mawdesley & 11 \\
3 & Laubscher & 16 \\
\hline
\end{tabular}

Based on the analysis of the influence of size-shape characteristics of the undercut on the range of values of the HR of caving, the length-width ratio parameters of the undercut for the Udachnaya pipe were determined (Table 2).

Table 2 Acceptable proportions of sides of the horizontal undercut

\begin{tabular}{llllllllll}
\hline Width $(\mathrm{m})$ & 40 & 45 & 50 & 55 & 60 & 65 & 70 & 75 & 80 \\
Length $(\mathrm{m})$ & 360 & 180 & 129 & 104 & 90 & 81 & 74 & 69 & 65 \\
\hline
\end{tabular}


The dimensions of the rectangular-shaped undercut with sides $a$ and $b$ were calculated based on the value of the HR using the following relation:

$$
H R=\frac{a \cdot b}{2 a+2 b} \Rightarrow a=\frac{2 b \cdot H R}{b-2 \cdot H R}
$$

where:

$$
\begin{aligned}
\mathrm{HR} & =\text { hydraulic radius. } \\
\mathrm{a} & =\text { side of an undercut in metres. } \\
\mathrm{b} & =\text { side of an undercut in metres. }
\end{aligned}
$$

The height of Block $3 / 4$ is $200 \mathrm{~m}$ and is limited to the spacing of current development in accordance with the engineered solutions. The optimum height of the block is determined based on the estimated service life of the drawpoints and the estimated costs for reinforcement support of the draw-belled area and roadways. It should be noted that the mine plan and design include simultaneous development of the reserves at two levels of the Udachnaya mine. In this case, the minimum permissible distance between the front ends of developments are determined by the angle of the rupture or, at the stage of development of the undercut, the safe depth of work.

The level caving mining method for the extraction of reserves of the 200 Level includes two conditional stages of actual mining operations:

1. Initial stage.

2. Normal stage.

The initial stage of level excavation includes the formation of the drawbells simultaneously in two adjacent panels of the EOB. The drawbells in the WOB are formed after the undercut. Above the drawbells, the general undercutting is done by blasting of the drill rings drilled from the -650 Level (-640) into the compensation space of the drawbells. As the undercut advances and reaches the calculated area $\left(5,200 \mathrm{~m}^{2}\right.$ or more), caving of the kimberlite starts in the first block.

Afterwards, the normal stage of ore extraction in the level is carried out. This is done by involving the adjacent panels and joint blocks with faces divergent from the first quadruple block towards the ore boundary. As the adjacent panels are involved into the mining process, the undercut area will significantly exceed the minimum of $5,200 \mathrm{~m}^{2}$ required to initiate the caving. The caved ore is drawn through the drawbells opened in compliance with the required size-shape parameters to ensure safety. Broken ore is loaded at the drawpoints and loading ramps on the -665 Level and hauled using load-haul-dumpers.

Two options (base case and alternative) of the block caving method are considered to extract the reserves. They differ from each other in terms of block sill development design, different laying-out of transport, haulage, undercutting, and drilling drifts, but the general mining sequence and system stay the same.

The classic caving method featuring double undercutting level has been considered as the preferred option.

\section{Options of draw level configurations}

The design with double undercutting is aimed at reducing the risk of ore hang-up in the block at the beginning of mining. By blasting the holes of the top undercutting level, the additional fragmentation takes place at the block sill. Despite the extra expenses on mining preparation, it allows to reduce the oversize rock at the initial stage of caving process as well as to exclude possible interruptions in mine production (Benjavski 1990). Simulation of stress distributions in the formation of single and double undercutting is shown in Figure 7. 


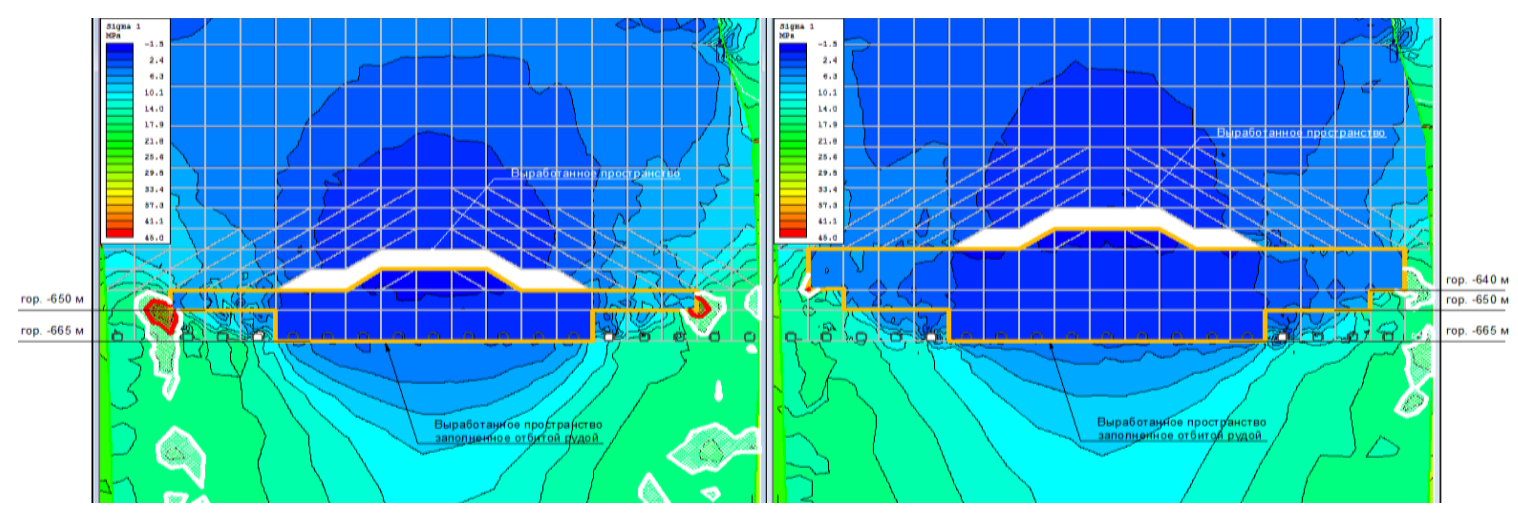

Figure 7 Distribution of the stresses during single and double undercutting

The panel mining is carried out by divergent fronts towards the flanks of the orebody. In the process of mining of the first two panels, the adjacent panels are also involved in extraction.

The general design of development of the levels includes the following operations:

- -665 Level: driving of main crosscuts, loop haulage drifts, loading ramps.

- -665 Level: driving of haulage drifts spaced at 40 (35) m along panel boundaries.

- Driving of loading ramps between haulage drifts.

- Construction of drawpoints above loading ramps during stoping.

- -650 Level (-640 Level): undercut level. Driving of drilling (undercutting) drifts along the panels.

Under this option, the panel stoping begins with the top undercutting of the block. For this purpose, the drifts of the top undercut level are driven at the centre of each panel. Using these drifts, the drilling, breaking and partial draw of broken ore is carried out. Initially, the rings of the top undercut are blasted to form the pre-splits (only one is formed for the panel), and subsequently to release the previously broken ore.

The main parameters of the double chevron-shaped undercutting are:

- Loading ramps are arranged diagonally to the drawbells.

- Spacing of the haulage drifts is $35 \mathrm{~m}$.

- Spacing between loading ramps and drawbells is $15 \mathrm{~m}$.

- Dimensions of joint panel block is $15 \times 35 \mathrm{~m}$, footprint is $525 \mathrm{~m}^{2}$.

- The bottom undercut level is located at the -650 Level.

The main difference of this option is the sequence of development. In order to reduce the accumulated abutment pressure in the elements of block sill, the drawbells are formed after top and bottom undercutting. For proper undercutting and maximum ore extraction of the block, the design of the bottom undercutting was changed at all stages of the mining. The so-called 'chevron-shaped' bottom undercut with rings drilled from the lower undercut level was used. When the top undercut level is developed, such a design of lower undercutting simplifies the ore draw process at the initial stage of block mining. The oversize rock is also reduced (Malofeev 2007). 
Figure 8 shows the scheme for developing the basic excavation block and panel as a whole under this option.
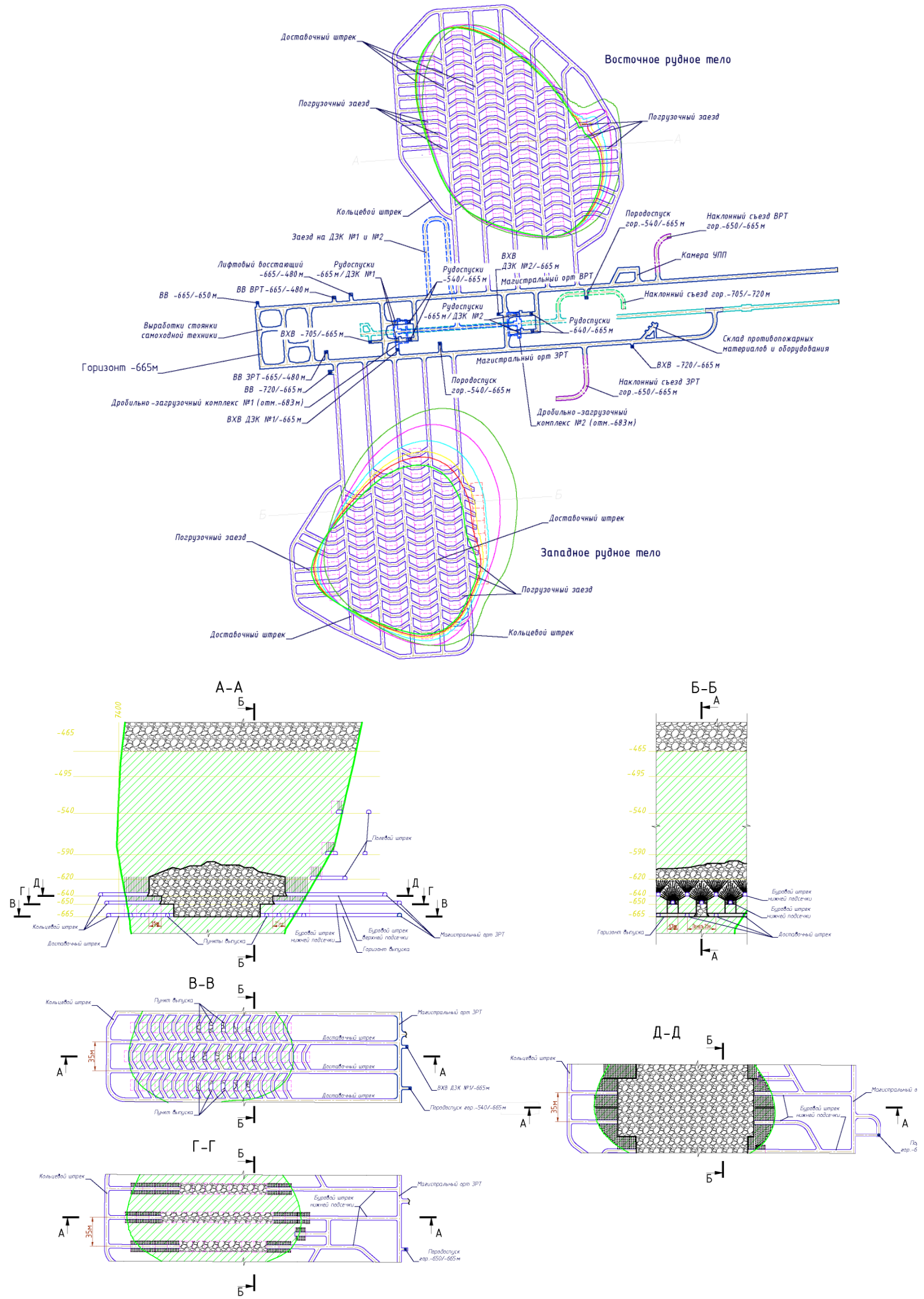

Figure 8 Cave mining system 
Advantages of the option with the double chevron-shaped undercut include:

- Maximum ore extracted from the block.

- Minimal loss of ore between drawpoints (draw ellipsoids).

- Minimal risks associated with hang-ups of ore mass at the initial stage of block development (at the start of caving).

- Minimum oversize yield.

Disadvantages of the option are:

- The largest scope of roadway and level development.

- Cross-drifts to the drawpoints at an angle of $60-70^{\circ}$ to the haulage roadways increase the concentration of stresses at adjacent sections of the ramps and loading drift.

- High indention of the stope sill increases the risks of rock pressure impact on the stability of mining system elements (stump pillars).

- High costs of support and maintenance of haulage roadways and draw drifts.

- Drawbells can be opened only after undercutting the block in order to limit the rock pressure impact on the stump pillars and drawbells.

- In comparison with the base case option, it is necessary to develop and maintain an additional undercut level, which makes haulage of the ore more complicated.

- Increased amount of drilling to undercut the block.

At present, solutions are being developed to establish extraction indicators for the release of ore under caved waste rocks for the classical parameters of the development systems under consideration using mathematical modelling, with the discrete elements method. The results of the mathematical modelling are shown in Figure 9. In the problems to be solved, the assessment of loss and dilution of ore was performed when the limiting dilution was reached in the last batch (portion, cycle) of 50,70 and $80 \%$. It should be noted that the values obtained for loss and dilution of ore are valid for the adopted technologies and their parameters, provided that the caved overburden rock is a waste rock (i.e. there is a protective rock). According to the preliminary results of the simulation, the losses will be $10.7 \%$, dilution $-12.9 \%$.

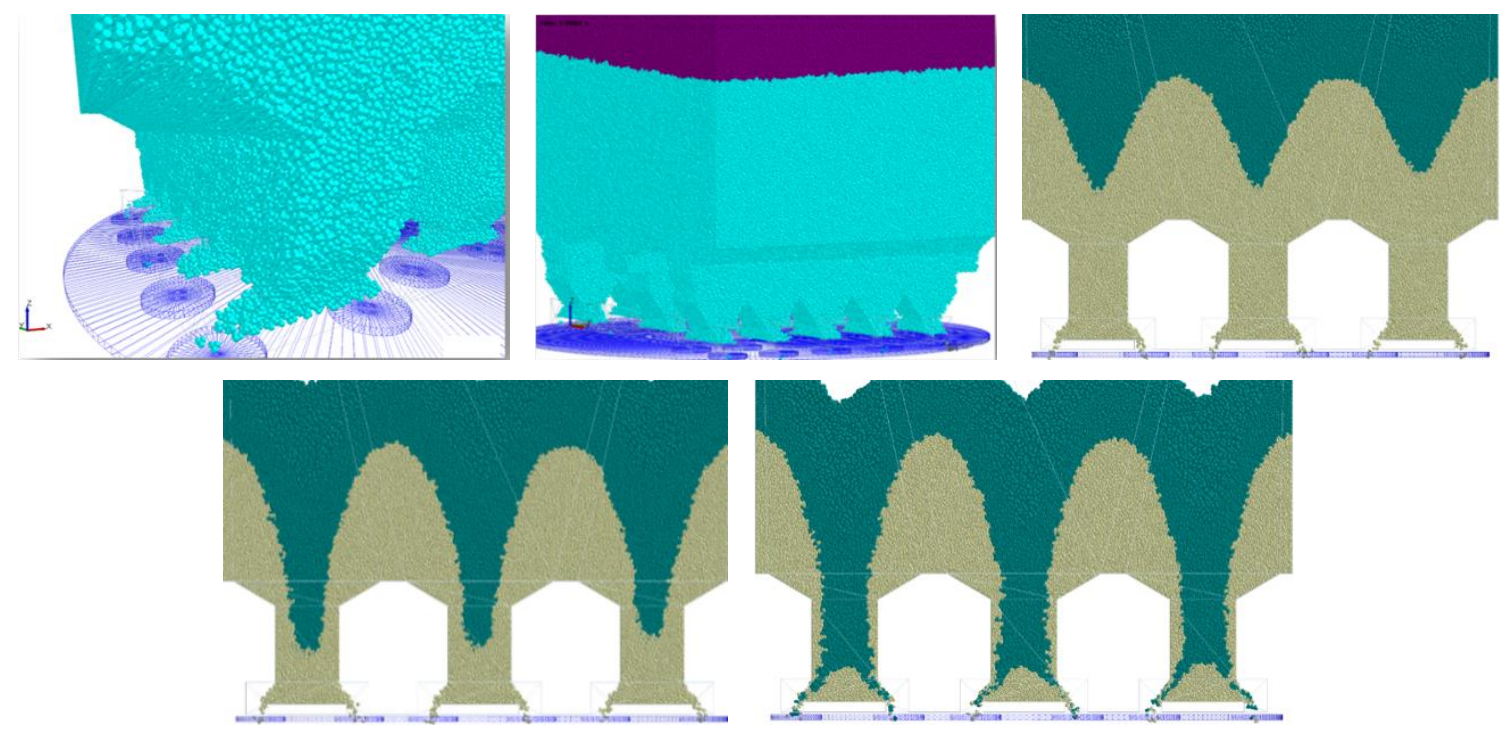

Figure 9 Fragmentary results of mathematical modelling of the draw for the system of level block caving 


\section{Conclusion}

From experience of block caving mining operations, the option involving the formation of a bottom undercut ahead of the formation of the drawbells may result in the ore becoming over-consolidated and hang up at the drawpoints. Caving with double undercutting includes the development of a top undercut level and allows for opening of the drawbells ahead of the advance of the bottom undercut, due to the formation of the stress shadow above the draw level. This ensures the stability of the stump pillars and the normal initiation of caving.

Therefore, at the initial stage of development the cave mine design option with double undercutting in the $W O B$ and $E O B$ is more attractive. Despite the higher costs of drilling and maintaining the production level and the draw level, the advantage of this option is the minimal loss of ore and the maximum volume of ore extraction from the block.

Thus, the proposed double undercutting option with haulage drift spacing of $35 \mathrm{~m}$ and loading ramps spacing of $15 \mathrm{~m}$ is the optimal design for cave mining development of the two orebodies of the Udachnaya kimberlite deposit at the $-480 / 680$ Level.

\section{References}

Benjavski, Z 1990, Upravlenie Gornym Davleniem, Mir Publishers, Moscow, p. 254.

Brown, E 2002, Block Caving Geomechanics, Julius Kruttschnitt Mineral Research Centre, The University of Queensland, Brisbane, p. 515.

Laubscher, D 2001, 'Cave mining - state of the art', in WA Hustrulid \& RL Bullock (eds), Underground Mining Methods, Society for Mining, Metallurgy \& Exploration, Englewood, pp. 455-463.

Malofeev, D 2007, Development of the Theory and Practice of Ore Drawing Under Caved Rocks, Siberian Federal University, Krasnoyarsk, p. 171.

Mawdesley, C 2002, Predicting Cave Initiation and Propagation in Block Caving Mines, PhD thesis, The University of Queensland, Brisbane. 